\title{
The Perception of Gender Inequality and Lived Experience of Women: The Case of Iranian Women in Maragheh
}

\author{
Roghayyeh (Aysan) Panahi* \\ Ph.D Cultural Sociology, Science and Research Branch, Islamic Azad University, Tehran, Iran \\ Samad Abedini \\ Assistant Professor of Sociology, Khalkhal Branch, Islamic Azad University, Iran
}

\begin{abstract}
This study aimed to evaluate the "perception of gender inequalities in the lived experience of women in Maragheh". The main question raised is: do women perceive gender inequalities in their lived experience and interpersonal relations? What are the contexts for the perception of gender inequalities? In addition, what cultural, social, and individual factors mostly affect gender inequalities in women? The research method was integrative, phenomenological, and survey. In-depth interviews were performed in winter 2015 and questionnaires were filled in fall 2016 in Maragheh. In addition, theoretical sampling and two-stage stratified sampling were used for qualitative and quantitative information, respectively. In the quantitative section, the reliability was estimated at above 0.7 for all variables. According to the qualitative results, the contexts for perceiving gender inequalities include: 1) society, 2) traditions and customs, 3) emotional attention, 4) nutrition, 5) clothing, 6) education, 7) facilities, 8) gender-related work and role-playing, 9) respect and appreciation, 10) purchasing toys, and 11) social interactions. In addition, the regression test results demonstrated that the socialcultural factors and age predicted $32.8 \%$ of the variance of the dependent variable, and the value of the correlation between the values predicted by the equation was 0.573 . Furthermore, the highest and lowest impact factors were related to cultural capital (0.282) and age (-0.096), respectively.
\end{abstract}

Keywords: Perception of Gender Inequalities, Social-Cultural Factors, Lived Experience

DOI: $10.7176 /$ RHSS/10-1-02

Publication date: January $31^{\text {st }} 2020$

\section{Introduction}

Lived experience is a concept in social sciences that has attracted attention to how people experience and discern everyday situations/life (Berglund 2007; Daher et al. 2017 Quoted from Vandenbussche et al. 2019: 3). Lived experience is not just related to immediate experience and not the pre-reflection of events; rather, it is related to an experience that has been lived through. Alvesson \& Skoldberg (2000) argue that lived experience is not a passive and sensitive phrase and rather a series of perceptions completed as a rule with interpretation in the form of goals, values, meanings and the like (Quoted from Vandenbussche et al., 2019: 3). Therefore, lived experience concerns the way a person discerns and attaches meaning to what has happened, informed by past experiences and cultural repertoires (EASTMOND, 2007; THROOP, 2003, quoted from Vandenbussche et al., 2019: 3). Following C. Jason THROOP (2003), there is general adherence to a complemental model of lived experience, which believes that lived experiences can be outlined in different forms across a spectrum, ranging from coherent and unified experiences to fragmentary and disjunctive experiences. As such, lived experiences are not always described by ordered coherence and may also have a fragmentary structure (Vandenbussche et al. 2019: 3-4). Therefore, lived experience in the world also influences mental experiences. In fact, people's action in the community is affected by lived experience, and this experience in everyday life shapes and organizes the action of members in the society and its social structures, which itself is affected by gender. In other words, femininity and masculinity affect mental perceptions and structures, and consequently, influence people's actions in society and their experiences of daily life.

Erving Goffman $(1976,1977)$ argues that gender is a social classification and an organizational device in ritualized portrayals, or what is recognized as an identity dialog function. According to Goffman, no gender is necessary. In terms of gender awareness, he mentions that only one might properly state that there is no gender identity here (Quoted from Irvine, 2003: 448). For Goffman, gender practices have formed a social classification of what is known as sex-class. It is a "gender displays" that is mostly not allowed to express the natural differences between the two genders based on the production of those differences. Other socialists, such as Candace West and Don Zimmerman argued in the meetings of the American Sociological Association (1977) that gender is not an inherent trait; therefore, it is a routine accomplishment (Irvine, 2003: 449). According to Goffman, gender social classification production in the society is followed by gender practices, meaning that each gender must display behaviors appropriate to that sex and function based on these behavioral methods in its gender classification.

In other words, gender is not a biological matter but a social structure evolved throughout the history of 
humanity. This structure has led to different definitions for the role of women and men since childhood, in a way that each sex is expected certain behaviors from society. Therefore, different norms are institutionalized in girls and boys during the socialization flow (Njogu and Orchardson-Mazrui 2009: 2). By adolescence, people know what society expects of them and act based on these expectations. However, sex is a biological discussion and refers to gender differences between men and women. Nonetheless, these differences are not the reason for women's inability and acceptance of so many inequalities.

Inequality is defined as the distinction between individuals in a society based on natural and biological differences (e.g., skin color and gender), that results in discrimination and inequality in the community. We face gender inequality in society if the differences are based on the gender of individuals. Therefore, gender inequality is discrimination between male and female genders in the community and during socialization. This gender inequality has led to the exploitation and colonization of one sex by another throughout history, and the exploited have always been the women.

The gender inequality of suppressing women has been known as a social, historical and describable phenomenon. Social and family institutions that are derived from material forces (e.g., private property) lead to male domination and female obedience, and these materialist forces maintain gender inequality. Many societies are constructed in a way that women are economically dependent on men. The idea that says gender inequality is embedded in family, cultural, economic, political, and social structures is often recognized as a patriarchal and social system that serves men's dominance over women (Burn, 2011: 3-4). In general, the unequal distribution of opportunities, resources, and awards based on gender is called gender inequality (Reskin and Padavic 1994 Quoted from Ngo et al. 2003: 229).

Given the fact the gender is a social-historical structure, gender inequalities are, consequently, socialhistorical structures. By referring to the lived experiences of women, we realize that women perceive gender inequalities in their social interactions in the community owing to their mental structures and awareness. In other words, women's perceptions of their lived experiences and interactions help them recognize gender inequalities and discriminations existing in the community and culture and lead to their intrinsic understanding of women's social position and status in the community. Perception of gender inequalities is defined as the perception that a human being or a group of human beings - women in this case - attains by observing inequalities in opportunities, social situations, access to social equality, and resources. Evidently, this perception results in gender inequality perception if affected by individuals' gender.

Wulansari believes that gender inequality is not an individual problem but rather a major social issue in our time. Therefore, the mentioned researcher has conducted an in-depth study of social structures. Moreover, gender inequality interacts with all institutions and organizations in human societies, from marriage, family, work, economics, politics, religions to arts and other cultural products, even language (Wulansari, 2013:1). Inequalities are not only revealed through socialization. The obvious gap in politics, legal frameworks, and investment opportunities have complicated showing women's potentials in social, economic and political areas. Nonetheless, the economic independence of women is an important part of bridging inequalities, preventing violence, and fostering confidence and prosperity. Economically independent women are more assertive and demand their rights (Njogu and Orchardson-Mazrui, 2009: 2).

Gender inequality is rooted in human history and is undeniable. However, the concept can be interpreted in different ways due to the presence of various social-cultural structures in communities. In other words, gender inequalities are defined and interpreted based on the perception of these inequalities. In the present study, we sought to recognize the perception of gender inequalities in women at the various age group, income levels, educational level, place of residence and community class with various cultural capital and social opportunities. Given the different foundations of this perception in various societies, it seems that the perception of gender inequalities must be identified in all human societies with various ethnicities, cultures, and ideologies so that we could understand the mentality of women in terms of these inequalities. By doing so, we might be able to eliminate and reduce these inequalities in the community despite this perception, which would ultimately lead to the prevention of some problems in the society caused by gender inequalities.

In the area of gender inequality, people experience everything and think based on their perceptions of their gender that exist in society. In other words, women would perceive no gender inequalities and would show no reactions when there was no discrimination and inequality in the social structures of the community. Therefore, if there were no social inequalities, in particular, gender inequalities, in social structures, individuals in society would have no perception of inequality due to a lack of experience, thought, or perception of inequality. The actions and reactions of the members of society would also be different from what is seen today.

While several studies have been conducted on gender inequality in Iran, no research has been performed to interpret the perception of gender inequality in this country. In the present study, we aimed to evaluate the perception of gender inequalities in women's lived experiences in the country. Therefore, not only no research has been conducted on perception of gender inequality in the country, but also as Wulansari puts it in an article: "while several articles in the field of perception of gender inequality are performed on the effect of gender 
inequality on other social realities, such as psychological consequences in education (Shehu, Kasale, and Moreri, 2012), psychological consequences (Kinias and Kim, 2012), developing perception of children and adolescents (Neff, Cooper and Woodruff 2007), elite perception in Norway and Sweden (Teigen, 2009), division of payment and non-payment of work and dissolution of participation in Sweden (Olah and Gahler, 2012), gender quality learning program (Alim and Rashid, 2005), and representation of women in parliament in South Africa, Uganda and Zimbabwe (Jacobs, 2009), few studies have addressed how perceptions of gender inequality are actually perceived by individuals and how they differ across countries (All Quoted from Wulansari 2013: 3).

The present study was performed in Maragheh, East Azerbaijan province. The city of Maragheh is one of the most ancient cities of Iran, citizens of which have their own specific culture, civilization, customs and traditions that have made them different from the people of other cities in Azerbaijan province. Therefore, we aimed to assess the perception of gender inequality of the women in this city. Since the main goal of this integrative research (qualitative in terms of phenomenology and quantitative-survey) was assessing various aspects of perception of gender inequality in lived experiences of women both in childhood and after that, we applied an in-depth interview and phenomenology to explore this perception and mentality of women regarding gender inequalities within and outside the family of women of different ages (18-79 years) and with various levels of education. After conducting and analyzing the interviews by researchers, the contexts of these gender inequalities were identified and examined.

Therefore, in the qualitative part of the research, we aimed to recognize different contexts for the perception of gender inequalities in the lived experience of women in Maragheh and to explain the perception of gender inequalities in the lived experience of women in Maragheh based on their mentality in a phenomenological way. In the quantitative part of the study, we aimed to determine the effect of different factors on various contexts of perception of gender inequalities in the lived experience of women.

Therefore, the main question is this: do women perceive gender inequalities in the experience of their own lives and interpersonal communication? What are the contexts for the perception of gender inequalities? Which cultural, social, and individual factors are most affected by women's perceptions of gender inequality? In other words, we sought to find an answer for the question of: is there a significant relationship between cultural capital, access to equal social opportunities, body management, social identity, membership in social networks, and age and the variable of perceptions of gender inequalities in the lived experience of women in Maragheh?

\section{Research Background and literature}

Several studies have been conducted on gender inequality in the past few years. In this regard, the studies by Saroukhani and Mahmoodi (2008), Dehnavi and Mo"jdFar (2005), Sadaqati Fard and Sakhamehr (2013), Salehi et al. (2013), and Nabavi and Ahmadi (2007) are among the researches performed in Iran to directly and indirectly assess the factors and consequences of gender inequality in different fields. Gender inequality appears to be the focus of this research. While gender inequality was considered the dependent variable in some of the mentioned studies, it was regarded as the independent variable in other studies. Nonetheless, none of the aforementioned studies evaluated and recognized the perceptions of gender inequality in the country using an integrative approach (qualitative-quantitative). The majority of studies have assessed the factors affecting the perceptions of gender inequality and have emphasized the causal process.

- In a research entitled "gender inequality perceptions: a comparative study of women in Japan and Indonesia" ", Wulansari (2013) evaluated methods where gender inequality is perceived by Japanese and Indonesian women through using a sociological perspective. This scholar concluded that Japanese respondents tended to perceive common sex as unequal. On the other hand, Indonesian respondents considered sexual relations as equal. This is the opposite of what is expressed by Blumberg, where social terms of sexual equality might guide women to perceive the existing sexual relations in their communities, such as being equal, regardless of their demographic, social characteristics. In the present study, we aimed to find reasons for this lack of agreement by a sociological analysis of socio-cultural factors prevalent in Japan and Indonesia. In addition, after an in-depth interview with Japanese and Indonesian women, Wulansari realized that some socialcultural factors should have been considered if the finding is to be comprehended adequately. These factors included: 1) a cultural ideal of female upbringing and limited social structures based on the gender division of labor in Japan, and 2) a diverse gender ideology based on ethnicity, religion, family values and social structure enables an extended or supportive family support system in Indonesia. It is worth noting that the mentioned study involved a model that was different from the Blumberg hypothesis regarding the relationship between the terms of sexual equality and gender equality perceptions of women (Wulansari 2013: 25-26).

- Gender inequality was also evaluated in a research by Ngo et al. (survey study). The first result was related to the perception of gender inequality at the workplace. In addition, the results demonstrated that individual-level variables explained only three percent of the variance. Moreover, gender (not job position and organizational commitment) had a significant effect on the predicted direction. All organizational-level variables, with the exception of organizational size, had stronger effects on perceived gender inequality and explained $16 \%$ 
of the variance. In line with previous studies, it was shown that women and men had different perceptions of the existence of gender inequality at the workplace (Gilligan 1982; Gutek et al. 1996; Rotundo et al. 2001 Quoted from Ngo et al. 2003: 237).

- In a research by Condie et al. (2006) on gender inequalities in schools of Scotland, there were genderrelated inequalities in these centers (Condie et al., 2006).

Women considered the culture of their work group as highly masculine, aggressive, competitive, and selfpromoting in a research by Joanne Martin and Debra Meyerson (1998) on high-level professional women in a computer development firm. In the mentioned study, while women had invented ways to cope with this work culture, they did not get a sense of belonging at work (Quoted from Acker 2006:445).

All of the mentioned studies all homogenous in terms of focusing on the perception of inequality and lack of identification of the contexts for the perception of gender inequalities. Meanwhile, we aimed to recognize the contexts for the perception of gender inequalities in the present study. Moreover, the sample population of all of these studies are in other countries and have different cultures and no ethnic diversity such as Iran.

\section{Theoretical Approach}

The necessity of perceiving inequality is having a certain level of awareness ${ }^{1}$, which (Ritzer 1996; Kolakowski 1981; Giddens 1973) must include awareness of the status of subsidiary groups, as well as socio-cultural and demographic characteristics. Sometimes, all of these features affect the perception of gender inequality. On the other hand, the perception of gender inequalities can affect awareness. Given the fact that male dominance is markedly different in different societies and within societies between different groups and ethnicities, the perception of gender inequality can be different as well. It could even be expressed that the level of male dominance in the community affects the perception of gender inequalities at the individual level. Awareness of these differences and inequalities can result in a higher perception of gender inequalities in the community and inside families (between spouses and children). Even in workplaces, these gender inequalities enhance perceptions of inequality.

Since some levels of gender inequalities in the society and at the macro level are in male dominance ${ }^{2}$ (Blumberg, 1984: 7), perception of gender inequalities can also lead to perceptions of these inequalities at the micro-level. These inequalities, which are at the economic, political, social and even ideological levels, affect women's perceptions. While women perceive gender inequalities (Blumberg and Coleman 1989; Turner 1998:233-234), this perception is reduced due to the social status of women in society, which is an inferior social status. This is mainly due to the fact that women at the macro level do not have much access to the interests and resources of power to consolidate their dominance. Therefore, the perceptions of gender inequality in women are affected by knowing that they always face unequal opportunities in the economic and political sectors. The more the economic power of women, the higher their perception of gender inequalities. In contrast, the fewer women's power in the community and family and the higher male dominance, the less perception of gender inequalities by women.

Women will also have relative power at the micro and macro levels when entering the economics and being able to gain a position independent of men in the society layering ${ }^{3}$ (Turner, 1998: 238-240). Over time, this relative power advances towards equality of power between men and women. Men will also react to prevent women from achieving this equal power. Therefore, it can be argued that the socio-political status of women gives them an awareness of their social status and the ability to perceive gender inequalities. This awareness of social status decreases in women with low economic power. Sometimes, women have no perception of gender inequalities in their position and consider it the first status.

Given that society is stratified by gender, and with regard to gender inequalities in the community, we are facing gender inequality stratifications. However, gender stratification changes when equal opportunities and a similar level of resource access are provided to men and women. In addition, changes in various structures and variables affect women's status in society, in a way changes in previous states of women lead to altered situations and better opportunities in the community, all of which are unwanted. Nonetheless, the elite, women and intellectuals have been able to change this gender stratification status consciously and willingly. In other words, women have acknowledged a number of expectations by getting job opportunities out of the house. When faced with unfulfilled expectations, they experience inequality that has been shaped and reinforced throughout history by changing gender definitions. This issue led to the efforts of women to change this gender stratification. However, given the support of male domination with an ideology, while most women perceive gender inequalities in the community, their motivation and efforts have not completely changed the gender stratification in the community or reduced inequalities. These circumstances may have been well deduced by feminist theorists.

\footnotetext{
${ }^{1}$ Giddens and Marx theory of awareness

${ }^{2}$ Blumberg's Theory of Gender Inequality

${ }^{3}$ Chafetz Theory of Gender Inequality
} 
According to feminist theories ${ }^{1}$ (Ritzer, 1996:308-335; Higgins, 2004; Vukoičić, 2013; Jeffreys, 1990; Lorber, 1997: 9-13; Frederick, 1992; Mackinnon, 1990, 1983 and 1982; Raymond, 1990; Kappeler, 1990), it is argued that since women have different socialization process, compared to men, their lived experiences are different as well. This difference in the behavior of women is due to their different socialization caused by the community's culture. Gender division of labor has also affected women's performance since women have always been active in the private sector and men in the public sector. Therefore, women have more limited lived experience, compared to men, which affects the social behaviors and performance of women. In addition, women suffer from alienation because of the exploitation of women working in the home and the private sphere. Inequality in women is even observed in the field of private property, which intensifies gender inequalities. Therefore, gender inequalities existing in society are perceived when women are aware of their social status, have not gained their true status in society, and there are no spaces and places for the exchange of ideas and information in society.

A social sphere ${ }^{2}$ (Stevenson 2002; Ritzer 1996:412-417) is required for women to freely talk about gender inequalities with other women and men, who protest against gender discrimination, and raise their awareness in this regard. This sphere is an open space for the exchange of thoughts and discussion of various issues, and people participate in these discussions freely without fear of harassment. These discussion spheres are either physical spaces for conversation or virtual spaces provided by the Internet and more advanced mass media. The spaces created in virtual spaces provide a more democratic space for the expression of actors' ideas. This virtual space is an opportunity for creating information networks so that residents are able to exchange their views and thoughts.

Therefore, the public sphere is the field of communication and the exchange of ideas, which creates an environment for communication and information flow that leads to the formation of public opinion. The public opinion can be shaped and flowed in physical or virtual social networks, where citizens and participants can use these thoughts to raise their awareness. It should be pointed out that cyberspace that has its own specific users affects the knowledge of individuals, increases their sensitivity to their surrounding problems, and raises their awareness of their surrounding environment. One of these perceptions is perceiving gender inequalities existing in society. The use of these spheres and their level of effectiveness depend on the level of education, the applied socio-economic base, and age groups. However, physical social networks are made up of all actors and citizens with different levels of education and socioeconomic bases and are classified based on these variables and even gender. For example, illiterate women in the age range of 40-55 years are the average classification of the physical-supportive social network for its members.

Therefore, since different forms of socialization are used for women and men in different classes, "membership in physical social networks and groups is formed and continues based on gender ${ }^{3}$ (Bastani, 2007)." These social interactions and relations affect feminine and masculine behaviors and traits. Joining these networks and groups also affects information availability, where access to information results in successes and achievements for individuals in today's societies. However, membership in virtual networks is not based on gender and is a network in which all age, gender, occupation, and class groups can be found. As such, there is no gender stratification in virtual networks, compared to physical networks. By joining virtual networks, women can achieve a certain level of awareness and react based on their knowledge level.

Since women are different social spheres and have an inferior position in society, compared to men, they have different perceptions, meaning that what makes women's mentality is not biological issues, but rather their lived experiences and effect of social sphere form their mentality, according to which women react in society. Because, in society, women are more restricted than men and in fact, structural constraints are imposed on them, which results in their different perceptions and awareness. However, if women are able to come together in society and more experience masculine social sphere can have mentalities similar to men and be more aware and have more perceptions of different issues, such as men and women's status in society and the existing inequalities among them.

According to Bourdieu's mind approach (Ritzer 1996:400-412), human perception and thoughts are affected by the infrastructures of economic, cultural and symbolic power in the behavior, speech and perception of the actors, affecting all social relations. In addition, it impacts the amount of people's capital in acquiring social powers. Social status and different situations affect the behaviors of individuals. Moreover, changes in social conditions affect and modify the perception and behavior of the actors. Actors perceive and understand the world based on mental structures, and shape, reform, and reproduce their mental structures in different situations based on social situations and structures. People re-internalize their mental structures shaped during their socialization. They use these concepts in their social reactions and behaviors and react based on them. The social status and

\footnotetext{
${ }^{1}$ Feminist theories include feminist theories and gender inequalities, gender differences, gender inequalities, liberalism, Marxism, gender oppression, radicalism, and socialism.

${ }^{2}$ Habermas Public Sphere Theory

${ }^{3}$ Theory of gender and social networks
} 
position of people shape their mental structures, help the formation of their attitude and perception of society, and organize their behavior in the organization. In society, one learns how to perceive different social situations.

Bourdieu believes that the frameworks that give people practical insights to perceive and act in a social environment are in fact character or Habitus that enable individuals in various situations to perceive the social world unconsciously and react based on them. Therefore, Bourdieu argues that mental structure is a social phenomenon since it is constructed and developed based on social and class structures of individuals, and this mental structure has been shaped over time. In this respect, perception of gender inequalities arises in individual action once the psyche refines various conditions and is affected by the social status of individuals in society. In other words, the human mind that enables human perceptions is able to adjust individual behaviors based on structures and infrastructures. A person feels frustrated and perceives gender inequality in society when he fails to find his desired position according to his mental perceptions. As such, perception of gender inequalities is related to the mental and social structures of individuals, as well as the interactions between these structures. Man, who has always been going back and forth between the mind and society and his mental structures shapes the community and vice versa, will perceive inequality when his social status and position is not the one for which his mental structure is defined, compared to others. Not only the perceptions of individuals but also all features of people, especially their social identity, are affected by their mentality.

The social identity constructed by the social interaction of individuals affects the social reactions of people, which, in return, emerge based on various perceptions and mentalities of individuals. All of these are effective in shaping and re-creating social and individual identity. Given the fact that every person in society has different social roles and each person deals with different roles in various interactions and social situations in the public and private spheres, each person has different and combined identities, and these distinct identities create different perceptions in each person. Since women are faced with playing different roles both as a person and a group in society, they have different identities that encompass distinct perceptions. According to the Intersectionality theory (Veenstra 2011:1-3), it could be argued that the identification of individuals in society is affected by inequalities in society. The more these inequalities become severe and individuals have the power to communicate between the disparate components, the more they will perceive gender inequalities. In that situation, one can compare men and women and evaluate their own status in relation to others, especially men, in society. In the end, gender inequality is perceived when inequality is perceived, even in power relations, and the status and social class of women is understood.

According to the identity theory by Burke and Tajfel (Jenkins, 2008), it could be expressed that gender inequality perceived in women is due to the social participation and status, or distinct social roles between men and women in the community and social groups, which emerges as distinct and different identities. This distinction between identities manifests itself in the perception of gender inequality if it is seriously at odds with the perceptions and semantic systems of individuals in society. This perception of gender inequality is presented as body and face management in the discussion of social-individual identity. In this respect, women manage their bodies to present a different face of their identity and their real self and perform social behaviors different from their real identity and have different identities in various roles in society. Therefore, face and body management sometimes occur to show different identities in various social roles in society. This is mainly due to the fact that body and face are one of the social-individual identity manifestations, meaning that the way a person rises to the occasion and presents himself affects his individual and social identity.

Moreover, Bourdieu considers the body as a comprehensive form of physical capital that includes a distinctive social status and symbolic forms and regards the purpose of body management to be assessing the status, differentiation, and basis of acquisition. In his analysis, Bourdieu refers to the commodification of the body in modern societies and its appearance as physical capital (Shilling, 1993:127). In addition, he associates individuals' identities with social values consistent with size, shape, and appearance (Shilling, 1993:14). In Iran, body management has increased the perception of gender inequalities among women in the past years. This issue has gone beyond the individual actions and reactions, and this body management is sometimes monitored on a macro level in the country. While body management is an individual domain in social and everyday communication in most foreign countries, it has become an area of government intervention in Iran. In fact, today's legislative device of the country has issued some laws for body management, most of which are related to women. That is, in our society, women are no longer able to manage their bodies and make decisions related to their bodies. In addition, women are expected not to enforce a decision other than the laws adopted regarding controlling their childbirth, method of childbirth and abortion.

One of the demographic characteristics affecting gender inequality perception is age. According to Chafetz's theory, different age groups have various impacts on people's opportunities, including women. In other words, population expansion, including that of women at a certain age, can take socio-economic opportunities from some women or all classes of women, whereas the decrease of the population can increase these opportunities and facilities. Therefore, women's perceptions of gender inequality in society arise from life experiences, as well as individual actions and reactions in social spheres, the structures of which seek to impose 
some issues on women based on cultural differences in various countries and attempt to stabilize or intensify inequalities in society. Therefore, sometimes in societies, such as Iran, unequal opportunities, from educational and occupational chances to body management, evoke more of these inequalities. The more women have cultural capital and stronger socioeconomic bases and the more they use social-physical networks, especially virtual networks, and the stronger their social-individual identity, the more they are able to perceive gender inequalities (look at conceptual model 1).

\section{Research Methodology}

The present study aimed to find answers for some questions in two qualitative and quantitative parts: in the qualitative section, it is asked: what are various contexts and aspects of gender inequality perception in the lived experience of women? and, do women perceive gender inequality in their lived experience and the flow of interpersonal communication? In the quantitative section, it is asked: cultural, social, and individual factors mostly affect the perception of gender inequality? In other words, we sought to find the answer for the following question in the quantitative section: is there a significant relationship between cultural capital, access to equal social opportunities, body management, social identity, using social networks, age and perceptions of gender inequality in the lived experience of women in Maragheh, Iran?

The present study was carried out in two stages using an integrative approach (qualitative-quantitative). In the first stage, qualitative thematic interviews were conducted with 23 women living in Maragheh, the result of which was the perception of gender inequality from the viewpoint of interviewees after referring to their lived experience in society, extracting suitable components, and constructing tools and items for the perception of gender inequalities. In the second stage, the research was implemented in Fall, 2016 on 420 women in Maragheh aged above 18 years (statistical population of women in Maragheh was 61142 people [Statistics Center of Iran, 2012]) as survey (quantitative method) using questions related to cultural capital, access to equal social opportunities, body management, and using social networks. It is notable that the sample size was estimated using the Cochrane's formula.

In this study, sampling was two-stage in terms of stages and judgmental and quota in terms of method of selection. In the first stage, a number of residential units were selected based on the welfare level (neighborhood or district). In the second stage, the number of respondents assigned to each residential unit was estimated using the quota method. In this respect, we distributed the sample size proportional to the population size of women in each unit so that the sample composition matches the population composition. Therefore, we calculated the quota for each residential unit of the whole sample, including the number of respondents (look at Table 1). Afterwards, the questionnaires estimated by quotas were completed by the researcher at homes of participants by random simple method.

\subsection{In-depth Interviews}

In this study, we conducted in-depth interviews with 23 women in Maragheh aged 18-79 years. After receiving consent from the participants, the interviews were recorded and, notes were often taken during the interviews. In the end, the interviews were transcribed and primarily coded. Theoretical saturation was achieved after the transcription of the interview with the 23rd participant, which resulted in the ceasing of interviews. Following that, the lived experiences of the participants regarding their perception of gender inequality were analyzed, resulting in the identification of 250 primary codes, 13 primary subcategories, seven secondary subcategories and three main categories, including emotional-family, individual-cultural, and social-political. The interviews had semi-structured questions, and during the interviews, we asked questions based on the participants' responses in order to persuade them to share their lived experiences of perception of gender inequalities existing in society and families. On the other hand, the interviewees described their mentalities based on their lived experiences in life. In addition, the descriptions of the participants were emphasized during the process to help recognize various aspects of perception of gender inequalities.

\subsection{Research Tools}

In order to construct the index of perception of gender inequality, we first conducted in-depth interviews (23 interviews) with women in Maragheh, the result of which was familiarization with perception of the concept from the viewpoint of women and extraction of components using Colazzi method to analyze the phenomenological data (Abu Shosha, 2010). After data collection at the pretest stage, the items related to the perception of gender inequality were tested using the factor analysis method. In this context, all of the remaining items for the perception of gender inequalities had $\geq 0.5$ factor load.

After approving face validity, the reliability of the tool was also confirmed using Cronbach's alpha. In addition, a Cronbach's alpha of 0.862 was estimated for 78 items of gender inequality perception index, which was indicative of a relatively high reliability for the index. In addition, the index of equal social opportunities was 0.802 with 20 items. Meanwhile, some items of the indexes were eliminated to obtain the final Cronbach's 
alpha. In this regard, Cronbach's alphas of cultural capital (21 items), body management (13 items), social identity (eight items), and social network membership (12 items) were estimated at $0.735,0.601,0.644$, and 0.785 , respectively. At first, the total alpha was estimated at 0.818 for 164 items. After the elimination of some items, Cronbach's alpha was calculated at 0.833 for 155 items (look at Table 2). These results demonstrated that the questionnaire assessed the desired variables. Given the fact that the coefficients were above 0.6 , it could be concluded that the questions related to "the perception of gender inequalities in the lived experienced women" had the necessary reliability to continue the research.

\section{Results}

Research results are presented in two qualitative and quantitative sections.

A) Qualitative Results ${ }^{1}$

The study's first question was: what are the contexts for the perception of gender inequalities in lived experiences of women? Do women perceive gender inequality in their lived experience and the flow of interpersonal communications? At first, the interviews were carefully transcribed to understand the contexts and aspects of perception of gender inequalities. Afterwards, general semantic units were revealed by summarizing the participants' statements. At this stage, the researchers aimed to create units that are close to the language of the responders as much as possible. After this stage, the units of each question were determined, followed by categorization and receiving the main themes (look at Table 4).

Before generally describing the interviews, we explained the demographic characteristics of 23 responders in Table 3.

According to Table $3,47.8 \%$ of the participants were in the age range of $20-35$ years, whereas $43.5 \%$ and $8.7 \%$ were in the age ranges of $36-60$ and $61-76$ years, respectively. In addition, $52.2 \%$ of the participants had diplomas or below diploma degrees while $47.8 \%$ of them had associate and higher degrees. Moreover, $60.9 \%$ of the responders were unemployed and only $39.1 \%$ of them were employed.

\section{A-1) In-depth Interviews}

According to the results of in-depth interviews, the perception of inequality was observed in interviewed women, and this perception formerly existed in various age groups and has increased in the age range of 18-79 years. In these interviews, women talked about their perception of discrimination, which most of the times caused hatred and frustration, even with their gender. Some of the women wished to be a boy from childhood to adulthood. In some interviews, the subjects considered gender inequalities to be caused by the culture and economic structures of societies in the past. Since male children would help in farming and animal husbandry tasks and income earning, parents more wanted to have a boy and always supported their male children. These inequalities have become the dominant culture throughout history. With the passage of time and the changing economic structures, employment and income of the father of the family, unemployment of male children in most families, family income by the father and sometimes the mother, there is no change in the dominant culture of most families. Even if there has been a change, women have perceived gender inequalities due to the formation of social and economic structures for the benefit of men and to the detriment of women throughout history.

The perception of gender inequality among women is often out of the micro and family level and is observed at the macro and social level in our country owing to the existing inequalities in rules and socialpolitical structures. Interviewed women expressed their hatred of these laws in the country that is established for the benefit of men and at the expense of women. A great deal of these discriminations and inequalities are observed in family law issues (e.g., divorce and child custody), as well as inheritance and Diyat ${ }^{2}$ (blood money). The interviewees believed that the law must be changed to reduce these inequalities. According to some interviewees, these legal inequalities are rooted in Islamic law, and our country's laws have also been derived from Shia Islamic jurisprudence. Despite the perception of gender inequality among women, the government and men often think that women do not think this way and have completely accepted the inequalities due to a lack of expressing them throughout their life. However, in-depth interviews with these subjects revealed that women completely perceive gender inequalities with all of their existence. Nonetheless, while they are used to these discriminations and inequalities due to lack of power, this acceptance in families is feminine, meaning that women raise their children in a way that there is no inequality between male and female children in the family. On the other hand, there were women who experienced beating and cursing by their husbands but tell young women with similar husbands (or misbehaving ones) that: "I tolerated these behaviors, but you should not tolerate". However, sometimes, there are women who not only do not accept this inequality but also show their perceptions in most cases by their actions and sayings. Some women even take steps to fight and reduce inequalities.

\footnotetext{
${ }^{1}$ The qualitative section results are fully presented in another article. In this paper, we summarized the results of the in-depth interview.

${ }^{2}$ Diyat for women: with the efforts of female activists, women's Diyat related to traffic accidents has been considered at the equal amount of Diyat for men. (Diyat means the price to be paid by the offender due to damage to organs caused by: murder, injury to one organ or all body parts accidentally or intentionally).
} 
Finally, it should be said that the main source of gender inequalities in the world - especially Iran - have been religious, cultural, social, economic (especially labor and income), political, security, and other structures, which has led to the formation of gender inequalities in culture and, consequently, the laws and socio-political structures of today. Despite changes in economic structures, from farming to industrial and services, in most countries of the world, including Iran, and regardless of changes in attitude toward women's employment outside the home, the prevailing culture and existing laws support gender inequalities. These inequalities are even observed in social-political structures in developing laws (in the section on income from work, employment, Diyat, and inheritance). In general, all of these laws are for the benefit of men and to the detriment of women.

In Iran, the government has had a major role in the intensification of these inequalities and discriminations in recent decades. For instance, there has been a discussion of women's un-employment and housekeeping state in the past few years in order to make women stay at home, bear children, and do not attend public areas. This issue is heavily advertised in the country. If financial-economic structures change but social-political structures remain traditional, not only no change will be made in the current gender inequalities, but also cultural recency will be extreme and people will experience psychological tensions.

Today, the women of our society are more aware of the past and their attitude toward gender inequalities has been changed. Today, women know that they do not deserve these inequalities and believe that women should not be subject to misbehaviors, cursing and beating their husbands. In addition, women do not tolerate these behaviors like women in the past. Women are human beings as well and have rights equal to men. Therefore, they deserve to have a stress-free life. Therefore, one of the causes of the increased divorce rate in Iran might be a lower tolerance of life pressure and misbehaviors of the spouse in women. The word "divorce" is no longer taboo for women and girls. In fact, some of the interviewees aged above 70 years claimed that they would not tolerate their husbands' disrespect.

Other issues such as abusive behavior, disrespect, and beatings of husbands have no place in most women's lives because our women no longer want to live like their ancestors. They like and urgently want husbands to treat them with respect and dignity and do not want to be disrespected only because of being a woman. Some of the participants pointed out that they would reciprocate their husbands' beating or disrespect. In general, women seek to revenge the misbehaviors of their husbands in their acts and words, which shows the change of behavior and attitude of women toward the current culture in Iran. In the past, women thought that they deserve to be beaten by their husbands and did not consider it bad. The same belief emerged in their daughters. Some of our participants tolerated their husbands' beatings and disrespect for some reasons but did not agree with them and considered them a kind of disrespect to women and their dignity.

Today, even if there is gender inequality in the social-political structures of Iran, and the government seeks to intensify these inequalities instead of reducing them, the informed women of Iran have attempted to deal with these inequalities regardless of the severe perception of gender inequalities in the country. By doing so, it is hoped that the next generations would not perceive this level of discrimination and inequality. In this respect, one of the solutions is upbringing children, especially boys, who are against these inequalities and often fight them and take steps toward equal gender-related rights. Such women who have no fear of pointing out their perception of gender inequality, talk about and criticize these issues in their families with their children and even with other women. By doing so, they can raise awareness in their children and young women in neighbors, families and friends. In addition, they find the root of discrimination and gender inequality in Islamic and Iranian law in their discussions, considering them a cultural issue.

According to the interviews, women in Iran perceive gender inequality as the result of the ruling of a patriarchal and religious system ideology on cultural, legal, political, social and even economic structures of the country. These ideologies have resulted in gender discrimination and inequality between men and women, and have caused the domination of belief of superiority of men over women in all structures, especially cultural and legal structures. In general, women under the law are treated as half a man in Iran and the word "complete human being" can be found in all Iranian laws, which is synonymous with the word "man". Women's right is half of a complete human being, meaning that women have half the wisdom of men, are incomplete and are recognized as the second gender. All of these beliefs have led to low self-esteem and self-confidence in women.

\section{B) Quantitative Results:}

\section{B-1) Descriptive Statistics:}

At first, we evaluated the demographic characteristics of 420 responders, the results of which are shown in Table 5:

According to Table 5, 38.3\% of the participants were in the age range of $18-30$ years, whereas $37.9 \%$ and $23.8 \%$ were in the age ranges of 31-49 and 50-79 years, respectively. In terms of the level of education, $61.4 \%$ of the subjects had diploma or below diploma degrees, while 30.5\% and $8.1 \%$ had associate degrees and BSc and higher education (MSc, PhD and higher), respectively. Regarding income level, $16.2 \%$ of the responders had an income of below 300,000 Tomans, whereas $12.6 \%, 18.3 \%, 48.1 \%$, and $4.8 \%$ had 301,000-700,000 Tomans, 701,000-1,000,000 Tomans, 1,001,000-5,500,000 Tomans, and $\geq 5,501,00$, respectively. In addition, there were 
$79.5 \%$ unemployed and $20.51 \%$ employed participants. Moreover, 23.8\%, 21.7\%, 25.5\%, and $29.3 \%$ of the subjects were residing in the marginalized, slum, affluent and middle-class neighborhoods, respectively.

\section{B-2) Inferential Statistics:}

The second question of the research is presented again: which cultural, social, and individual factors mostly affect the perception of gender inequality? Or, is there a relationship between cultural capital, equal social opportunities, body management, social identity, social network membership, age and perception of gender inequality in the lived experience of women in Maragheh?

According to the stepwise multiple regression table, the multiple correlation coefficient, coefficient of determination, and pure coefficient of determination were estimated at $\mathrm{R}=0.573, \mathrm{R} 2=0.328$, and $\hat{\mathrm{R}} 2=0.318$, respectively (look at Table 6). Since this figure corresponds to the stepwise regression, it is concluded that the impact factor of the index of equal social opportunities and body management was not significant and the impact factor of other coefficients was significant. By default, the impact factors of cultural capital, social network membership, social identity, and age were calculated at $0.282,0.121,0.268$, and -0.096 , respectively (look at Table 8). The regression equation obtained based on $\mathrm{F}=33.628$ and $\mathrm{P}=0.000$ was linear, and the regression was valid (Table 7).

The multiple regression test revealed that the social-cultural factors and age were able to predict $32.8 \%$ of the variance of the dependent variable (perception of gender inequality) in the lived experience of women in Maragheh, as shown by R2 in the third stage. The value of R or correlation between the values predicted by the equation was 0.573 . In other words, 0.573 of the predicted amounts was equal to actual amounts (look at Table 6). Considering the significance level obtained in all three stages, the values above the $95 \%$ confidence level were statistically significant. Given the ability of our model to predict $32.8 \%$ of the variance of the dependent variable with four variables of cultural capital, social network membership, social identity and age, which is an average amount in social sciences, the most important variables affecting gender inequality perception were cultural capital, social identity, social network membership, and age, respectively (look at Table 2).

Linear Equation:

$\mathbf{P G I}=82.574+0.425(\mathrm{CC})+0.262(\mathrm{SNM})+1.217(\mathrm{SID})-0.151(\mathrm{OLD})$

\section{Discussion and Conclusion}

According to the qualitative and quantitative results of the present study, there are various social inequalities in all societies, from class, racial, and ethnic inequalities to gender inequalities, all of which are based on the social construct of the community. In other words, capitalist and patriarchal ideologies in society throughout history have led to the formation of different social structures in ways that they have intensified inequalities, especially gender inequalities, and have resulted in gender stratification. Given the fact that individuals' mentalities and reactions in society do not operate in vacuity but form and continue in their interactions with structures, these mentalities and reactions shape and continue the mentioned structures.

In fact, social identity, character and mental structure of individuals are formed in their social interactions, which ultimately shape their reactions. Due to their gender, women occupy inferior positions in societies and are confined to private areas. In fact, women have dealt with unequal opportunities in all previous societies. This lack of presence in public areas and unequal opportunities have reduced women's power at all levels (economic, political, and social), and event in families. Therefore, women had no or little knowledge of their own and other women's status in society. Moreover, women's awareness led to the formation of equal social opportunities for women in society. Since educated women want fewer children, there will be a decrease in population in future generations, and the low number of women will increase occupation opportunities for women and will eliminate the gender-based division of labor.

The social and individual identities of Iranian women were changed by the rise of patriarchal religious and ideology following the arrival of Islam, due to the lack of social interaction between women. Given the fact that the social identity of people is affected by their social actions and mental structures, the lack of social interaction resulted in the inadequate building of women's mental structures and a number of problems in the social, even individual, identity of women. The result of the change in the social and even individual identities of women has resulted in a number of behaviors in women, one of which is their body management. In addition, women's social identity became unstable due to social and economic inequalities, as well as unequal opportunities and various social states of women, which could be associated with behaviors such as body management, which was formerly seen as using natural cosmetics but now involves cosmetic surgeries in addition to cosmetic products.

Moving forward in time and changes in economic, political and social structures altered people's culture and resulted in the gradual presence of women in public areas. Women's interactions and reactions with different structures and other society members increased by attending social areas, which ultimately raised society members' awareness. More public spheres were created for different social discourses in human societies in the 20th century after advancing in the field of mass media, especially computer and the Internet, and the formation of virtual social networks, which resulted in the shaping of different social groups. The social and mental 
interactions of women increased by developing these groups and membership of women in such groups, which was associated with the re-creation of social, and even individual, the identity of women in human societies.

These identity changes are emerged in the behaviors and reactions of women and are often associated with body management by women themselves. This body management, including interfering in the number of children and type of delivery, has resulted in government involvement in family and women's affairs. In fact, political and legal structures have attempted to shape the behavior and actions of women and even their mentality, resulting in the comparison of gender inequalities of women in Iran with the legal status of women in Western, and even Eastern, countries.

By raising the level of education in society and increasing the cultural capital of families, women were no exception and were able to raise their awareness by increasing their level of education. In addition, they were able to achieve a better social position in society, compared to women in previous years. These women were able to work outside the home and experience social opportunities equal to that of men. In addition, they affected their place of residence and socioeconomic base. All of these changes in the younger age groups led to an increase in the level of awareness of women in society since the more presence of these women in public environments, virtual and even physical social networks and participation in social discourse in public areas have led to the awareness of other women in society. As a result, women became more aware of gender inequalities in the country. In other words, the higher the level of awareness, the greater the perception of gender inequalities.

Increased level of education of women was associated with more presence in public spheres, virtual and physical social networks, an increase of cultural capital of families, more social interactions of women with social structures and society, and equal social opportunities. In addition, the mental structures of women were reformed and internalized. Women redefine their mental structures by finding their social status in society, and this re-organization of mind has changed and improved women's perception of the surrounding world and has raised women's awareness in society. Change of women's attitude toward the surrounding world led to more perception of various social inequalities in the world and society. In addition, these changes deepened and increased the perception of gender inequalities by women and they became able to more accurately perceive the contexts of gender inequalities.

In these perceptions, women understand various manifestations of gender inequalities against women in social structures and the rule of patriarchal and religious ideologies. In this context, the rule of men, whether in the name of God or the name of the power of men and fathers, has imposed various forms of inequalities on women throughout history. Today, different types of gender inequalities in society include gender inequalities in customs and traditions, rules, and norms, social interaction, private property and facilities, and even in men's respect and appreciation for women. All of this perception of gender inequalities is formed by women and reflects on their behaviors and actions when they establish knowledge and self-awareness about this issue. This cannot be achieved unless women have socioeconomic states in society and can benefit from equal social opportunities and be active in public areas.

The contexts of perceiving gender inequalities in society and the family have been identified, and all these aspects have led to perceptions of gender inequalities in women. These inequalities are occurring at different levels of society, across different social structures and within families, and sometimes also within today's families, where women are involved with unequal issues that often prohibit them from understanding daily issues. Women must first achieve "self-awareness and social awareness" and "achieve gender awareness for themselves" through social interactions and understanding the collective experience of these different gender inequalities. By understanding their social status and that of all women and by attaining collective and group awareness and self-awareness, women will realize the importance of their gender, and "perception of gender inequalities in oneself" will be changed into "perception of gender inequalities for oneself". Women at this stage can come to the conclusion that all of these gender inequalities are not only about themselves but also about all women as a group. If this perception is achieved in women, they can end gender inequalities.

Given the fact that cultural capital was one of the most effective factors in the research and had the most impact on gender inequality perception in path analysis and regression, cultural capital increases women's mental structures, awareness, and perception. In other words, women with higher cultural capital will more perceive gender inequalities. Women with high cultural capital are more likely to develop perceptions of gender inequality, compared to other women, due to more interactions with cultural structures, changed mental structures and access to a level of knowledge. In addition, the chance of reaching the "perception of gender inequality for oneself" from "perception of gender inequality in oneself" is higher in women with high cultural capital.

If women who are aware of women's rights and status inform other women in society and encourage them to fight for their rights, women will perceive gender inequalities by learning about their rights and similar experiences of social inequalities in the community due to their gender. In addition, women can achieve "the perception of gender inequality for themselves" by group experiences and comparing their status, dignity, and socioeconomic situations to men and the level of discrimination between women and men. As women's 
perceptions increase, they can address these inequalities at the public level.

In the end, it should be noted that the Iranian society and its socio-cultural structures are a society with patriarchal ideology, and women have suffered from severe gender inequality and discrimination in society throughout history, especially after the arrival of Islam in Iran. These inequalities have diminished or increased as we move forward to the present day. There were also governments in the Islamic Republic of Iran that aimed to reduce various pressures on women and corrected the law. However, in the following period, society has dealt with these women more harshly and has increased gender inequality and discrimination by passing and enforcing laws. In other words, while women in Iran might have been able to take a step forward, but they have taken two steps backward at other times.

Overall, it could be expressed that gender inequalities formed throughout history are social structures that can be changed. This is not possible without the efforts of knowledgeable women and informing other women to achieve the actual position of women in society in their social interactions. By raising awareness of other women, these women actually make changes in the mental structure of women and the social structure of society. Changes in social structures lead to women's mental restructuring, and this cycle continues, resulting in fundamental changes in all socio-cultural structures, norms, laws, customs, and traditions. All of these changes are associated with a change in women's social identity and an increase of their cultural capital and level of community awareness. As women's awareness increases, the perception of inequalities in society also increases. When women reach this level of perception of gender inequality and act as a group, they can gain perceptions of gender inequality for themselves. Awareness of women can reduce or eliminate the various social inequalities that are intertwined in human societies.

\section{Recommendations}

Given that, in these structures, women are confronted with different attitudes and ideas, even among men, they should make more extensive efforts to reduce gender inequalities. Women have no way but to gain more social awareness, for which they must strive to increase the level of cultural capital and education of all women. By educating future generations and realizing the importance of lack of discrimination and inequality between men and women, women can make more aware future generations so that they could achieve awareness for themselves and take steps toward the elimination of discrimination. One of the important tasks of all present and future generations is to eliminate gender inequalities in the fight against patriarchal ideology. In this respect, the only way is reforming the laws in all areas, including the laws related to men/women equality in family, inheritance, Diyat and testimony in court rights.

Focusing on the following practical suggestions from this study, it can help to improve the situation of gender inequalities and perceptions of these inequalities in society:

1. Given the existence of the perception of gender inequality in the lived experience of women, the authorities must take effective steps toward correcting this situation, one of which is correcting some laws in Iran. Some of these laws include:

1) Amendment of laws related to divorce, child custody, marriage laws (even temporary marriages), 2) Creating social freedoms and giving women some rights so that they can enjoy the right to cycling, motorcycling, and skating in cities like men, 3) Creating special places in stadiums for women so they can go to watch sports, including football, 4) Reforming the laws on inheritance and the right of women to testify in courts, where we always see women as half of the men, and fighting against these kinds of propaganda, 5) Reforming laws related to the employment of women in some jobs, such as the judiciary and presidency

2. True respect and appreciation for the human status of women

The main social processes are expected to be much larger and more complex in case of conducting more extensive empirical studies. Therefore, it is recommended that the contexts and levels of gender inequality perception be assessed at macro level (laws, social, economic, political, and cultural structures) in future studies in order to evaluate the level of perception of gender inequalities in educated women, distinct socioeconomic bases, and the intensity level of these perceptions and the impact of group differences on this perception. In addition, evaluation of the effect of these gender inequality perceptions on women's reactions and behaviors after the identification of contexts can be the topic of future studies. Each of these macro levels or the contexts of these levels can also be the subject of future research separately.

It should be noted that the perception of gender inequality has not only been in the past but also exists today and will continue to be today until the complete elimination of gender inequalities and discriminations in human societies. This will not occur with words and fundamental and cultural works are required to make a change. Socio-political structures must seek to change laws, regulations, as well as social and cultural norms of society. New social norms must be created and culture building is required so that women do not deal with so much discrimination and inequality in society. 


\section{References:}

Abu Shosha, Ghada .2010. "Employment of Colazzi's strategy in descriptive phenomenology: A reflection of a researcher". European Scientific Journal 8 (27): 1857- 7881. DOI: http://dx.doi.org/10.19044/esj.2012.v8n27p\%25p

- $\quad$ Acker, Joan.2006. "Inequality Regimes: Gender, Class, and Race in rganizations." Gender \& Society (Sage) $20: 441-465$. [Accessed: 2008/09/24].

DOI: $10.1177 / 0891243206289499$.

Bastani, Susan. 2007. " Family comes First:Men's and Women's Personal Networks in Tehran". Social Networks 29: 357-374. doi:10.1016/j.socnet.2007.01.004

Berkowitz, Leonard .1986. A survey of social psycology. $3 \mathrm{rd}$ ed. New York: Hot, Rinehart and Winston.

Blumberg, Rae Lesser. 1984. "A General theory of gender stratification". sociological theory, JSTOR 2: 23-101. DOI $\underline{10.2307 / 223343}$

Blumberg, Rae Lesser, and Marion Tolbert Coleman. 1989. "A Theoretical Look at the Gender Balance of Power in American Couples". Journal of Family 10 (2): 225-50.

Burn, Shawn Meghan. 2011.Women Across Cultures: A Global Perspective.3rd ed .New York : McGraw-Hill Companies.

- $\quad$ Condie,Rae, Alastair McPhee,Christine Forde,Jean Kane, and George Head. 2006. "Review of Strategies to Address Gender Inequalities in Scottish Schools." Final Report: Scottish Executive Social Research. Pp.173. ISBN 0755960394

- Dehnavi, Jalil. and Mo"jdFar, Sa"jd. 2005. "The Relationship between Gender Inequality and Social Mobility Motivation among Female Students". Quarterly Journal of Women's Studies 3(7): 51-76. (PERSIAN).

- $\quad$ Fineman, Martha Albertson. 2008. "The vulnerable subject: Anchoring equality in the human condition." Yale Journal of Law \& Feminism 20(1): 1-23.

https://www.researchgate.net/publication/228137515.

- $\quad$ Frederick, Danny .1992."Radical Feminism: An Expose." Libertarian Alliance Pamphlet (18). British Association of Librtarian Feminists Publication. ISSN 0953-7783; ISBN 185637131 x.

- $\quad$ Giddens, Anthony. 1973. The Class Structure of the Advanced Societies. 1 st ed. London: Hutchinson.

- $\quad$ Higgins, Tracy E. 2004. "Gender, Why Feminists Can’t (or shouldn't) Be Liberals". Fordham Law Review 72 (5) :1629-1641. http://ir.lawnet.fordham.edu/flr/vol72/iss5/12

- $\quad$ Irvine, Janice M. 2003. "The Sociologist as Voyeur: Social Theory and Sexuality Research, 1910-1978". Qualitative Sociology, Springer 26 (4): 429-456.

- Islamic Republic of Iran, Ministry of Housing and Urban Development. East Azarbaijan Housing and Urban Development Organization. 2011. Maragheh Development and Development Plan: Maragheh Population in the Census 2011. Maragheh Municipality Report Booklet References. (PERSIAN)

- Islamic Republic of Iran, Ministry of Interior. East Azarbaijan Governorate Deputy of Statistics and Information Office Planning. 2013. Detailed Results of the General Census of Population and Housing, Maragheh 6-1-2, 2011. Publisher: Bureau of Statistics and Information, East Azarbaijan Province Deputy of Planning. East Azarbaijan Governorate Site. (PERSIAN) https://www.ostan-as.gov.ir

- $\quad$ Islamic Republic of Iran, Statistics Center of Iran. 2012. Statistical Yearbook of East Azarbaijan Province. East Azarbaijan governorate site. (PERSIAN)

https://www.ostan-as.gov.ir

- Jeffreys, Sheila. 1990. "Sexology and Antifeminism." Pp.14-27 in The Sexual liberals and the attack on feminism, edited by D. Leidholdt and Janice G. Raymond, New york,Athene series: Teachers College Press.

- Jenkins, Richard. 2008 . Social Identity 3 rd ed. Abingdon-on-Thames: Routledge.

- Kappeler,Susanne. 1990. "Liberals, libertarianism, and the liberal arts establishment." Pp.175-183 in The Sexual liberals and the attack on feminism, edited by D. Leidholdt and Janice G. Raymond, New york,Athene series: Teachers College Press.

- $\quad$ Kolakowski, Leszek. 1981. Main Currents in Marxism: It,s Rise, Growth and Dissolution. Vol. I: Founders. (P. S. Falla, Trans). Oxford: Oxford University Press.

- Lorber, Judith. 1997. "The Variety of Feminisms and their Contribution to Gender Equality." Oldenburg: BIS, Bibliotheks- und Informationssystem der Universität Oldenburg 97: 7-43. https://www.google.com/search?ei=lwuSXarpHIzPwQLjmLu4Aw\&q

- $\quad$ MacKinnon, Catharine A.1982. "Feminism, Marxism, Method, and the State: An Agenda For Theory". 


CHICAGO JOURNAL, JSTOR, 7(3): 515-544. [Accessed: 09/07/2008].
http://www.jstor.org/stable/3173853

- MacKinnon, Catharine A .1983. "Feminism, Marxism, Method, and the State: Toward Feminist Jurisprudence". CHICAGO JOURNAL,JSTOR ,8(4): 635-658. [Accessed: 26/04/2010]. http://www.jstor.org/stable/3173687?origin=JSTOR-pdf

- MacKinnon, Catharine A. 1990. "Liberalism and the Death of Feminism".Pp.3-13 in in The Sexual liberals and the attack on feminism, edited by D. Leidholdt and Janice G. Raymond, New york,Athene series: Teachers College Press.

- $\quad$ Nabavi, Abdul Hussein, and Leila Ahmadi. 2007. "Investigating the Impact of Social Factors on Gender Inequalities in Family Symbols (inequality in decision-making power)". Iranian Journal of Sociology. 8(2): 59-82. (PERSIN)

http://www.jsi-isa.ir/article_23890_e320bbb1388306f5d0d1273f9b061096.pdf

- Ngo, Hang-yue, Sharon Foley, Angela Wong, and Raymond Loi.2003."Who Gets more of the Pie? Predictors of perceived Gender Inequity at work." Journal of Business Ethics, 45: 227-241.

- $\quad$ Njogu,Kimani., \& Elizabeth Orchardson-Mazrui. 2009 . "Gender Inequality and women's rights in the great lakes: can culture contribute to women's empowerment".1-22. [Retrieved December 15, 2015]. https://www.researchgate.net/publication/254308626.

- $\quad$ Raymond, Janice G. 1990."Sexual and Reproductive Liberalism". Pp.103-111 in The Sexual liberals and the attack on feminism, edit by D. Leidholdt and Janice G. Raymond, New york,Athene series: Teachers College Press.

- $\quad$ Ritzer, George.1996. Modern Sociological Theory. 4 th ed. New York: McGraw Hill Companies.

- $\quad$ Sadaqati Fard, Mojtaba, and Mitra Sakhamehr. 2013. "The Impact of Gender Equality on Women's Social Participation." Sociological Studies of Youth. 4(10): 43-60. (PERSIAN).

- $\quad$ Salehi, Mohammad Javad, Jafar Ebadi, and Goshtasb Mozafari. 2013. "The effect of human capital inequality in mele and female on economic growth in different areas of the world". Quarterly Journal of Research and Planning in Higher Education,19(3), pp. 41-62. (PERSIAN)

- Saroukhani, Bager, and Yosra Mahmoodi. 2008. "Reproduction of Gender Inequality in the Family: A Comparative Study of Employed and Housewives in Ilam City". Quarterly Journal of Social Research,1 (1): 47-61. (PERSIAN)

- $\quad$ Shilling,Chris. 1993. Body and Social Theory. London: Sage Publication.

- Stevenson, Nick. 2002. Understanding media cultures, Social Theory and Mass Communication .2 nd ed. London: SAGE Publications.

- $\quad$ Trigg, Roger. 2000. Understanding social science: a philosophical introduction to the social sciences. Hoboken: Wiley-Blackwell.

- $\quad$ Turner, Jonathan H. 1998. The Structure of Sociological Theory. 6 th ed. (Belmont, CA). New york: Wadsworth Publishing Company.

- Vandenbussche, Lieselot, Jurian Edelenbos, \& Jasper Eshuis. (2019). " Coming to Grips with Life-asExperienced: Piecing Together Research to Study Stakeholders' Lived Relational Experiences in Collaborative Planning Processes." Forum Qualitative Sozialforschung (FQS) 20(1):1-23. http://dx.doi.org/10.17169/fqs-20.1.3097

- Veenstra, Gerry . 2011. "Race, gender, class, and sexual orientation: intersecting axes of inequality and self-rated health in Canada". Veenstra International Journal for Equity in Health, 10 (3), 1-11. http://www.equityhealthj.com/content/10/1/3

- Vukoičić, Jelena .2013. "Radical feminism as a discourse in the theory of conflict." Sociological discourse 3(5) : 33-49. DOI: 10.7251/SOCEN1305033V

- Wulansari, Sri Ayu. 2013. "Gender inequality perceception: a comparative study of women in japan and indonesia." 49-127507: 1-28 Retrieved October 13,2014.

ricas.ioc.u-tokyo.ac.jp/aasplatform/achivements/pdf/2013_ab_16.pdf 


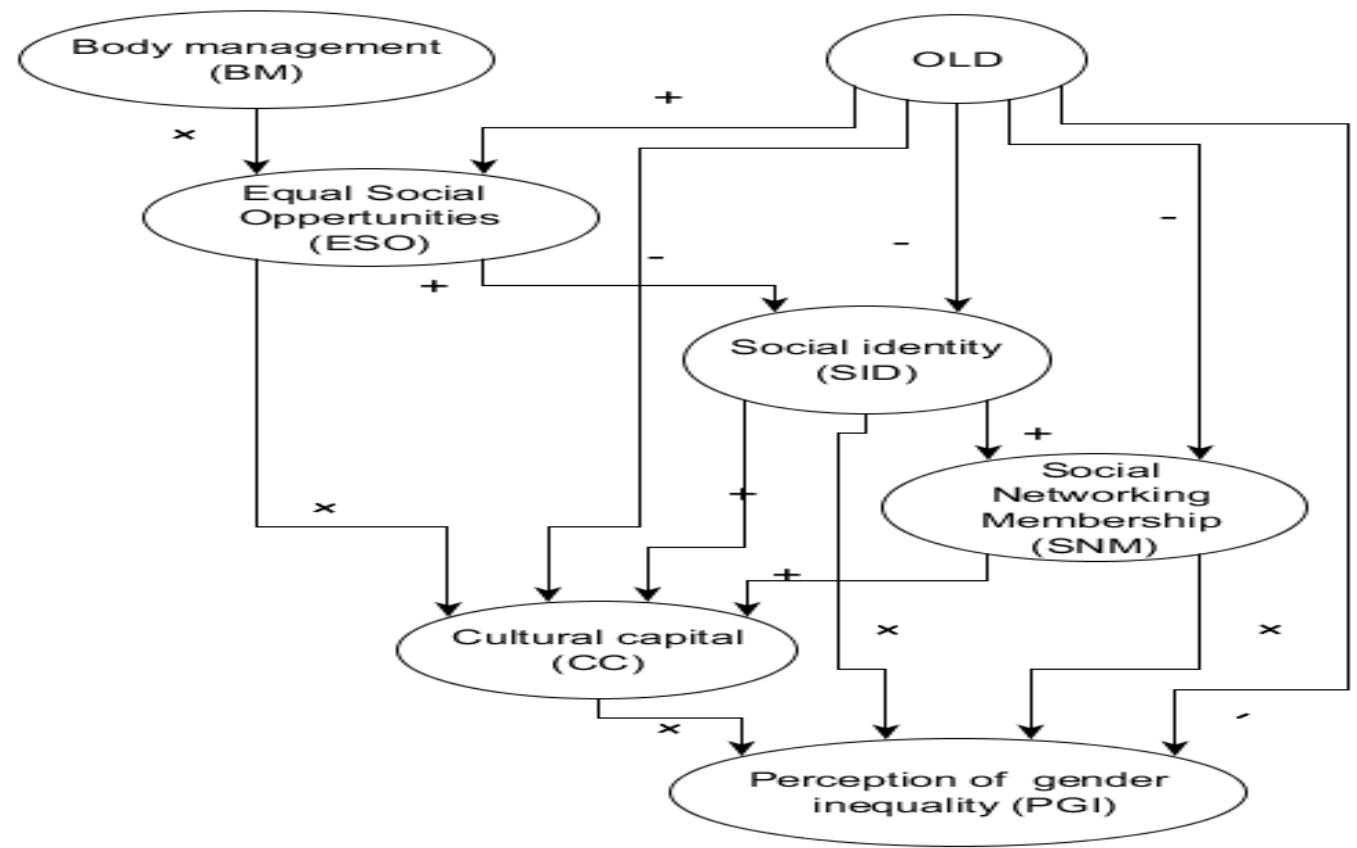

Model 1. Research Conceptual Model

Table 1. Population distribution of women aged 18-79 years based on selected residential units in Maragheh

\begin{tabular}{|c|c|c|c|c|}
\hline Residential unit & Welfare & Population & $\begin{array}{c}\text { Percentage distribution of } \\
\text { population }\end{array}$ & Sample \\
\hline The entire district 1 & Affluent neighborhood & 7825 & 14.95 & 63 \\
\hline $\begin{array}{c}\text { Neighborhood 3, } \\
\text { district } 7\end{array}$ & Affluent neighborhood & 1595 & 3.047 & 13 \\
\hline Region 1 , district 2 & Affluent neighborhood & 2103 & $4.0^{\prime}$ & 17 \\
\hline $\begin{array}{c}\text { Neighborhood 3, } \\
\text { region } 2\end{array}$ & Affluent neighborhood & 1570 & 3 & 13 \\
\hline The entire district 3 & Slum & 8547 & 16.33 & 69 \\
\hline $\begin{array}{l}\text { Neighborhood 1, } \\
\text { district } 7 \\
\end{array}$ & Slum & 1461 & 2.79 & 12 \\
\hline $\begin{array}{c}\text { Neighborhood 2, } \\
\text { district } 7\end{array}$ & Slum & 1432 & 2.73 & 11 \\
\hline The entire district 4 & $\begin{array}{l}\text { Marginalized } \\
\text { neighborhood }\end{array}$ & 12439 & 23.76 & 100 \\
\hline The entire district 6 & $\begin{array}{l}\text { Middle-class } \\
\text { neighborhood }\end{array}$ & 12226 & 23.36 & 98 \\
\hline $\begin{array}{c}\text { Neighborhood 2, } \\
\text { district } 2\end{array}$ & $\begin{array}{l}\text { Middle-class } \\
\text { neighborhood }\end{array}$ & 3135 & 5.99 & 25 \\
\hline Total & - & 52333 & 100 & 420 \\
\hline
\end{tabular}

Description for the above table:

Segmentation of columns of residential units and welfare status (Maragheh districts and areas) are derived of Maragheh development report (East Azarbaijan Housing and Urban Development, 2011). Other statistics are detailed results of population and housing of Maragheh (East Azarbaijan Governorate Deputy of Planning and..., 2013) and statistical yearbook of East Azarbaijan Province (Statistics Center of Iran, 2012) 
Table 2. Reliability (Cronbach's alpha) of items at the survey stage

\begin{tabular}{|c|c|c|c|c|}
\hline & \multicolumn{1}{|c|}{ Before item elimination } & \multicolumn{2}{|c|}{ After item elimination } \\
\hline Variables & $\begin{array}{c}\text { Number of } \\
\text { items }\end{array}$ & $\begin{array}{c}\text { Cronbach's } \\
\text { alpha }\end{array}$ & $\begin{array}{c}\text { Number of } \\
\text { items }\end{array}$ & $\begin{array}{c}\text { Cronbach's } \\
\text { alpha }\end{array}$ \\
\hline $\begin{array}{c}\text { Perception of gender inequality } \\
\text { (Pgi) }\end{array}$ & 78 & 0.861 & 78 & 0.861 \\
\hline Cultural capital (CC) & 23 & 0.674 & 21 & 0.735 \\
\hline Equal social opportunities (ESO) & 20 & 0.802 & 20 & 0.802 \\
\hline Body management (BM) & 16 & 0.572 & 13 & 0.601 \\
\hline Social identity (Sid) & 10 & 0.590 & 8 & 0.644 \\
\hline $\begin{array}{c}\text { Social network membership } \\
\text { (SNM) }\end{array}$ & 13 & 0.558 & 12 & 0.785 \\
\hline Total alpha & 164 & 0.818 & 155 & 0.833 \\
\hline
\end{tabular}

Table 3. Demographic characteristics of participants in the in-depth interview

\begin{tabular}{|c|c|c|c|}
\hline & Characteristics & Frequency & Percent \\
\hline \multirow{4}{*}{ Age } & $20-35$ & 11 & 47.8 \\
\cline { 2 - 4 } & $36-60$ & 10 & 43.5 \\
\cline { 2 - 4 } & $61-76$ & 2 & 8.7 \\
\cline { 2 - 4 } & Total & 23 & 100.0 \\
\hline Level of education & Diploma and below diploma & 12 & 52.2 \\
\cline { 2 - 4 } & Associate degree and higher & 11 & 47.8 \\
\cline { 2 - 4 } & Total & 23 & 100.0 \\
\hline Occupational status & Employed & 9 & 39.1 \\
\cline { 2 - 4 } & Unemployed & 14 & 60.9 \\
\cline { 2 - 4 } & Total & 23 & 100.0 \\
\hline
\end{tabular}

Table 4. Extracted categories and subcategories

\begin{tabular}{|c|c|c|}
\hline Phenomenon & $\begin{array}{c}\text { Main } \\
\text { categories }\end{array}$ & Primary subcategories \\
\hline \multirow{13}{*}{$\begin{array}{l}\text { Perception } \\
\text { of gender } \\
\text { inequalities }\end{array}$} & \multirow{4}{*}{$\begin{array}{l}\text { Emotional } \\
\text { and family } \\
\text { contexts }\end{array}$} & Discrimination in emotional attention \\
\hline & & Nutrition discrimination \\
\hline & & Discrimination in the purchase of toys \\
\hline & & $\begin{array}{l}\text { Discrimination in facilities (purchasing and allowance, equal opportunities, life } \\
\text { facilities, financial status, private property) }\end{array}$ \\
\hline & \multirow{6}{*}{$\begin{array}{l}\text { Individual } \\
\text { and cultural } \\
\text { contexts }\end{array}$} & $\begin{array}{l}\text { Discrimination in respecting and valuating based on gender (in kindness, sexual } \\
\text { relations, financial status of women, and violence) }\end{array}$ \\
\hline & & Discrimination in customs and traditions (making a proposal, virginity test) \\
\hline & & Discrimination in education \\
\hline & & Discrimination in socializing \\
\hline & & The process of changes in the feeling of gender inequality \\
\hline & & Creation of hatred and reaction in discriminated women \\
\hline & \multirow{3}{*}{$\begin{array}{l}\text { Social- } \\
\text { political } \\
\text { contexts }\end{array}$} & Discrimination in society (in laws and norms) \\
\hline & & Discrimination in clothing \\
\hline & & $\begin{array}{c}\text { Discrimination in gender work (gender-related division of labor and role- } \\
\text { playing) }\end{array}$ \\
\hline
\end{tabular}


Table 5. Demographic characteristics of responders at the quantitative stage (survey)

\begin{tabular}{|c|c|c|c|}
\hline \multirow{4}{*}{ Age } & Characteristics & Frequency & Percent \\
\hline \multirow{4}{*}{ Level of education } & $18-30$ & 161 & 38.3 \\
\cline { 2 - 4 } & $31-49$ & 159 & 37.9 \\
\cline { 2 - 4 } & $50-79$ & 100 & 23.8 \\
\cline { 2 - 4 } & Total & 420 & 100.0 \\
\cline { 2 - 4 } & Diploma and below diploma & 258 & 61.4 \\
\cline { 2 - 4 } & Associate degree and BSc & 128 & 30.5 \\
\hline Family income (Toman) & Total & 34 & 8.1 \\
\cline { 2 - 4 } & Below 300,000 & 420 & 100 \\
\cline { 2 - 4 } & $301,000-700,000$ & 68 & 16.2 \\
\cline { 2 - 4 } & $701,000-1,000,000$ & 53 & 12.6 \\
\cline { 2 - 4 } & $1,001,000-5,500,000$ & 202 & 18.3 \\
\cline { 2 - 4 } & $>5,501,000$ & 20 & 48.1 \\
\hline \multirow{4}{*}{ Occupational status } & Total & 420 & 100 \\
\cline { 2 - 4 } & Employed & 36 & 20.5 \\
\cline { 2 - 4 } & Unemployed & 434 & 79.5 \\
\hline Residential areas & Total & 100 & 23.8 \\
\cline { 2 - 4 } & Marginalized neighborhood & 91 & 21.7 \\
\cline { 2 - 4 } & Slum & 106 & 25.2 \\
\cline { 2 - 4 } & Affluent neighborhood & 29.3 \\
\cline { 2 - 4 } & Middle-class neighborhood & 100 \\
\hline
\end{tabular}

Table 6. Multiple regression test to determine the score of gender inequality perception Model Summaryb

\begin{tabular}{|c|c|c|c|c|c|}
\hline Model & R & R Square & Adjusted R Square & Std. Error of the Estimate & Durbin-Watson \\
\hline 1 & $.573^{\mathrm{a}}$ & .328 & .318 & 18.32182 & 1.602 \\
\hline
\end{tabular}

a. Predictors: (Constant), OLD, BM, SID, SNM, ESO, CC

b. Dependent Variable: PGI

Table 7. Variance analysis for determining the linearity of the regression equation ANOVA ${ }^{b}$

\begin{tabular}{|c|c|c|c|c|c|c|}
\hline \multicolumn{1}{|c|}{ Model } & Sum of Squares & Df & Mean Square & F & Sig. \\
\hline 1 & Regression & 67731.271 & 6 & 11288.545 & 33.628 & $.000^{\text {a }}$ \\
& Residual & 138639.669 & 413 & 335.689 & & \\
& Total & 206370.940 & 419 & & & \\
\hline
\end{tabular}

Table 8. Standardized or non-standardized coefficients of significant, dependent variables

\begin{tabular}{|c|c|c|c|c|c|c|}
\hline \multirow{2}{*}{\multicolumn{2}{|c|}{ Model }} & \multicolumn{2}{|c|}{ Unstandardized Coefficients } & \multirow{2}{*}{$\begin{array}{c}\text { Standardized } \\
\text { Coefficients } \\
\text { Beta }\end{array}$} & \multirow[b]{2}{*}{$\mathrm{T}$} & \multirow[b]{2}{*}{ Sig. } \\
\hline & & $\mathrm{B}$ & Std. Error & & & \\
\hline \multirow[t]{7}{*}{1} & (Constant) & 82.574 & 8.301 & & 9.947 & .000 \\
\hline & $\mathrm{CC}$ & .425 & .080 & .282 & 5.289 & .000 \\
\hline & ESO & .078 & .075 & .050 & 1.045 & .297 \\
\hline & SNM & .262 & .106 & .121 & 2.476 & .014 \\
\hline & $\mathrm{BM}$ & -.019 & .119 & -.007 & -.158 & .874 \\
\hline & SID & 1.217 & .204 & .268 & 5.955 & .000 \\
\hline & OLD & -.151 & .076 & -.096 & -1.978 & .049 \\
\hline
\end{tabular}




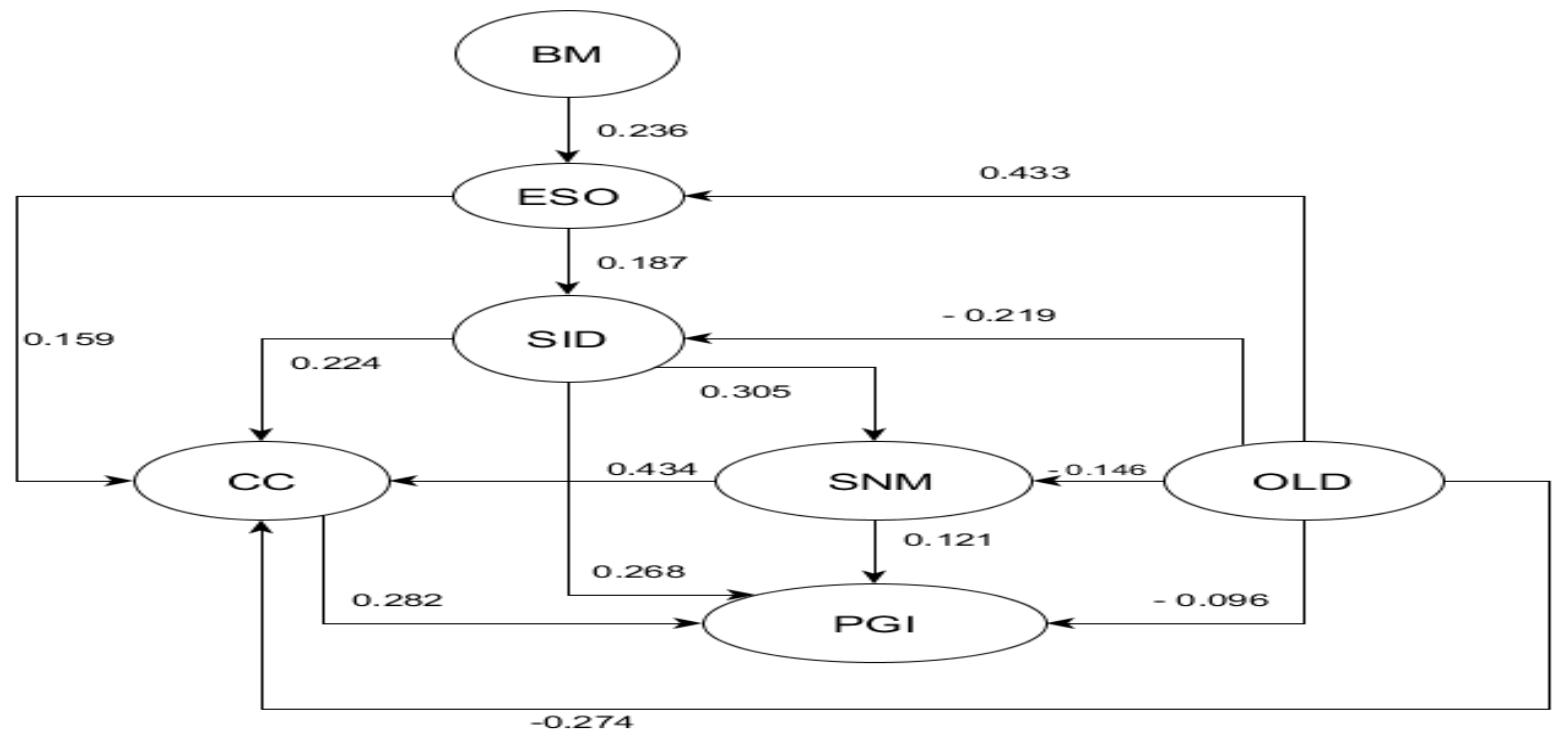

Model 2. Path Analysis

Perception Of gender inequality $(\mathrm{Y})=$ PGI

Equal Social Opportunities $(\mathrm{X} 1)=\mathrm{ESO}$

Body management $(\mathrm{X} 2)=\mathrm{BM}$

Social Networking Membership (X3)= SNM

Cultural capital $(\mathrm{X} 4)=\mathrm{CC}$

Social Identity $(\mathrm{X} 5)=$ SId

Old $(\mathrm{X} 6)=$ OLD 